Please do not remove this page

RMIT

UNIVERSITY

\title{
The how and why of plant-related fatalities in the Australian construction industry
}

Lingard, Helen; Cooke, Tracy; Gharaie, Ehsan

https://researchrepository.rmit.edu.au/esploro/outputs/9921858934001341/filesAndLinks?institution=61RMIT_INST\&index=null

Lingard, H., Cooke, T., \& Gharaie, E. (2013). The how and why of plant-related fatalities in the Australian construction industry. Engineering, Construction and Architectural Management, 20(4), 365-380.

https://doi.org/10.1108/ECAM-09-2011-0085

Document Version: Accepted Manuscript

Published Version: https://doi.org/10.1108/ECAM-09-2011-0085

Repository homepage: https://researchrepository.rmit.edu.au

(c) Emerald Group Publishing Limited

Downloaded On 2023/04/27 01:37:38 +1000

Please do not remove this page 
Thank you for downloading this document from the RMIT Research Repository.

The RMIT Research Repository is an open access database showcasing the research outputs of RMIT University researchers.

RMIT Research Repository: http://researchbank.rmit.edu.au/

\begin{abstract}
Citation:
Lingard, H, Cooke, T and Gharaie, E 2013, 'The how and why of plant-related fatalities in the Australian construction industry', Engineering, Construction and Architectural Management, vol. 20, no. 4, pp. 365-380.
\end{abstract}

See this record in the RMIT Research Repository at:

https://researchbank.rmit.edu.au/view/rmit:21367

Version: Accepted Manuscript

Copyright Statement:

(c) Emerald Group Publishing Limited

Link to Published Version:

http://dx.doi.org/10.1108/ECAM-09-2011-0085 


\title{
The how and why of plant-related fatalities in the Australian construction industry
}

\author{
Professor Helen Lingard ${ }^{1}$, Ms Tracy Cooke ${ }^{2}$, Dr Ehsan Gharaie ${ }^{3}$
}

\begin{abstract}
Purpose - Drawing on the findings of coronial investigations, this research aimed to investigate the circumstances and causes of fatal incidents involving plant in the Australian construction industry. The analysis sought to provide greater insight into how and why fatal incidents occur and to inform recommendations for the prevention of fatal incidents involving plant.

Design/methodology/approach - Fatal incidents involving plant were identified from the National Coronial Information System. In each case, the decedent was a construction worker and the incident occurred at a construction worksite. A systemic incident causation model developed by Loughborough University informed the identification of originating influences, shaping factors and immediate circumstances in each incident.

Findings - Most of the incidents involved excavators, trucks and cranes and that different classifications of plant were associated with different types of incident. The most common incident types involved people being run over by moving plant or struck by a moving object. Site layout and unsafe actions were the most commonly identified immediate circumstances. Shaping factors included site constraints and the design of plant, particularly visibility issues relating to 'blind spots.' Originating influences included the design of the permanent work and construction process.
\end{abstract}

Research limitations/implications - The research highlights the usefulness of systemic incident causation models, such as the 'Loughborough Model' in the analysis of the causes of fatal incidents involving plant in the construction industry.

Practical implications - The results indicate that plant-related fatalities occur as a result of a complex interplay of different causes, some of which are 'upstream' of the construction work. The use of innovative new site planning methods and active monitoring technologies to reduce the risk of collisions between people and plant should be considered.

Originality/value - The analysis provides a more detailed qualitative analysis of the causes of fatal incidents involving excavators than would is possible using national compensation data, which restricts analysis to a classification of the mechanism and agency of injury.

\section{Keywords}

Plant, fatalities, incident causation

\section{Introduction}

\section{Safety incidents involving plant}

Edwards and Holt (2009) define plant as "self-propelled off-highway machines (such as excavators and dumpers)" (p.337). Many safety incidents occurring in the construction industry involve the use of plant and other items of equipment (Gibb et al. 2005; Hinze et al. 2005). For example, McCann (2006) reports that over half $(52 \%)$ of fatal incidents occurring during excavation work are related to plant. After falls from height, plant incidents are the second most serious category of safety incident in the UK construction industry, accounting for approximately $20 \%$ of all incidents (Riaz et al., 2006). The types of plant most frequently involved in these incidents are telehandlers, dumpers, excavators and goods vehicles (Health and Safety Executive, 2009). In an analysis of incidents in the UK, occurring between 1986 and 1996, Edwards and Nicholas (2002) report excavators to be involved in more incidents/injuries than other type of plant used in construction, followed by dumper trucks.

In Australia the number of workers' compensation claims involving 'mobile plant and transport' in the construction industry was 1,455 in 2007/08, accounting for $10.1 \%$ of all claims. Further, the proportion of total claims involving 'mobile plant and transport' has remained fairly constant over the period between

\footnotetext{
${ }^{1}$ School of Property, Construction and Project Management, RMIT University, Australia

${ }^{2}$ School of Property, Construction and Project Management, RMIT University, Australia

${ }^{3}$ School of Property, Construction and Project Management, RMIT University, Australia
} 
$1997 / 98$ and 2007/08, indicating that the use of plant presents a persistent challenge for workplace safety in the Australian construction industry (see Figure 1).

Figure 1: Number of construction claims related to 'mobile plant and transport' agency of injury (Source: NOSI, 2011)

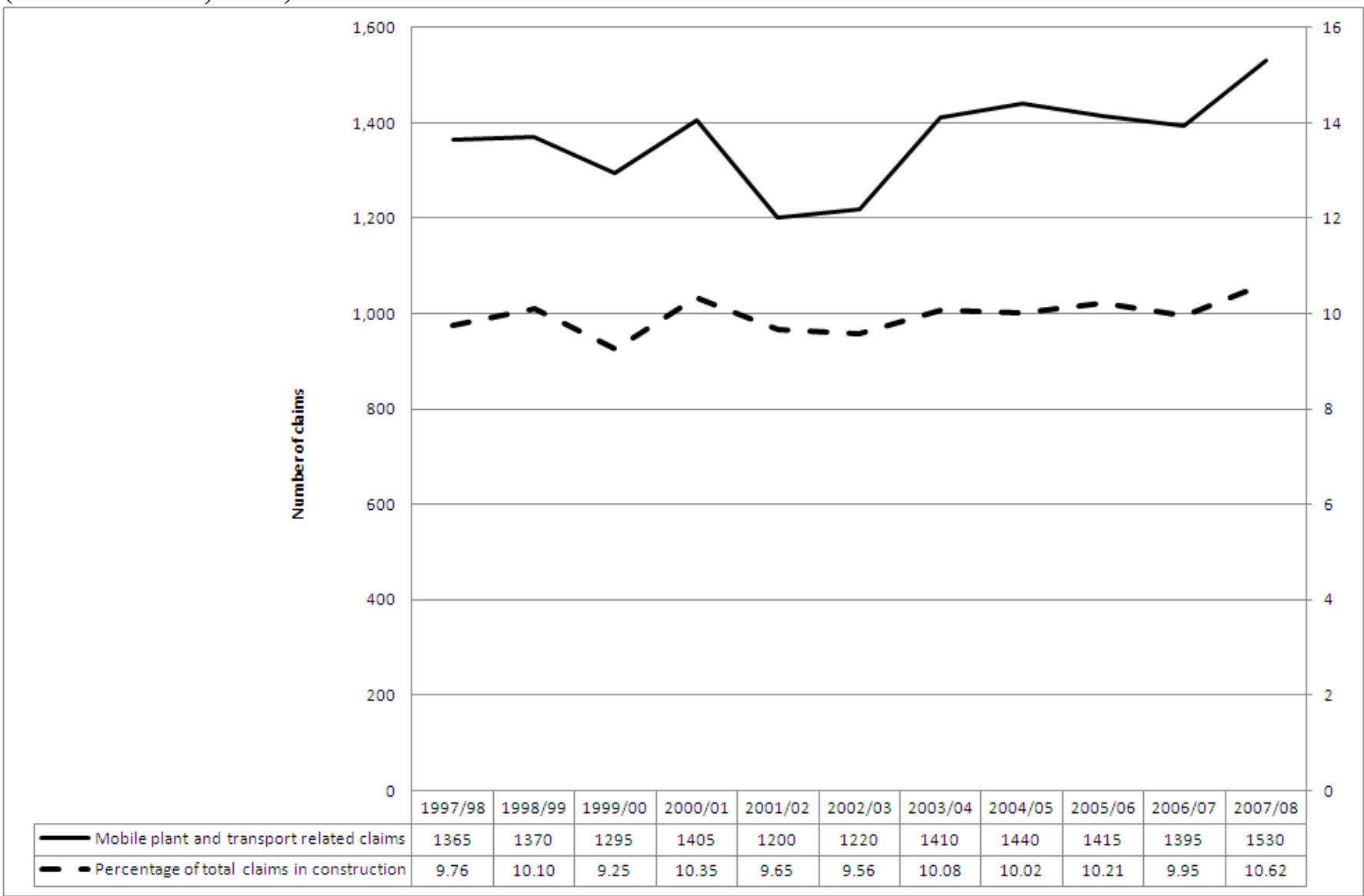

Previous research

Researchers have examined the nature and circumstances surrounding safety incidents involving plant and have identified common themes. These are summarised below.

Contact with machinery, material being excavated or being 'struck by' moving plant is responsible for over 15 deaths and 7,000 incidents per annum in the UK construction industry (HSE, cited in Edwards and Nicholas, 2002). A large proportion of incidents involving plant occur when a pedestrian or worker on foot is struck by a moving machine or one of its component parts. Arboleda and Abraham (2004) report that, after trench collapses, workers being struck by plant was the most frequent cause of fatalities during trenching work. McCann (2006) similarly reports that $57.5 \%$ of plant-related fatalities that occur during excavation work involve the decedent being struck by moving plant. 'Struck by' incidents involving plant accounted for 47 deaths and 361 major injuries in the UK between 2003/04 and 2007/08 (Health and Safety Executive, 2009). Indeed, Holt and Edwards (2011) identify 'struck by' incidents as the biggest cause of death involving plant and transport in the UK, accounting for $58 \%$ of fatal incidents in the reporting year 2007-08.

In the USA, Pratt et al. (2001) report that trucks account for $60 \%$ of 'struck by' deaths in highway construction. However, proportion of 'struck by' incidents involving trucks appears to vary between different sectors of the construction industry. Thus, Hinze et al. (2005) report that trucks account for $40 \%$ of 'struck by' incidents in the general construction industry, with backhoe/excavators accounting for a further $12.5 \%$.

Many items of plant used in construction have blind spots which prevent operators from seeing pedestrians in proximity to their machines. Blind spots are particularly common to the sides and rear of a 
machine (Teizer et al. 2010a) and have been identified as a factor in 56\% of visibility-related fatalities involving construction plant (Hinze and Teizer 2011).

Research indicates that the direction of travel is a factor in 'struck by' incidents (Edwards and Nicholas, 2002). Hinze and Teizer (2011) report that, in $72.6 \%$ of incidents in which workers were struck by moving plant, the plant was travelling in reverse. However, the proportion of incidents in which plant was travelling in reverse varies for different types of plant. Hinze and Teizer (2011) report that over 90\% of 'struck by' incidents involving skid steer loaders, water trucks, dump trucks and graders occurred when the machine was moving in reverse, compared to only $53 \%$ of incidents involving excavators.

Another common type of 'struck by' incident involving excavators occurs when workers are hit by an attachment that becomes unintentionally disconnected from the excavator 'arm'. Edwards and Holt (2008) report that these events are often the result of the incorrect use of a 'quick hitch' attachment mechanism.

A significant proportion of plant-related safety incidents involve the overturning of a machine (sometimes referred to as 'rollover' or 'turnover' incidents). Edwards and Holt (2010) state that a rollover involves a machine rolling over onto its side or end, i.e, through approximately 90 degrees from the vertical, while a turnover involves the machine turning right over, i.e., through more than 90 degrees. In the 2007-2008 reporting year, collapses and/or overturning incidents accounted for $18 \%$ of fatal incidents involving workplace transport in the UK (Holt and Edwards, 2011). In the USA, 58 compactor overturning incidents were recorded between 1986 and 2002 (Myers, 2004). Myers (2004) analysed these incidents and reports that almost half of these incidents involved 'smooth drum' type compactors that are prone to skidding. Further, compacting soil was found to be more hazardous than compacting other materials because of the risk of 'pockets' dropping under the weight of the machine. Working on a slope, using water as ballast and loading or unloading compactors from transport vehicles were also identified as risk factors for compactor overturn incidents (Myers, 2004). Edwards and Holt (2010) analysed the causes of overturning incidents involving mini-excavators, which are particularly susceptible to overturning due to their narrow width, dynamic forces and changing centre of gravity during operation. Factors identified as contributing to overturning in mini-excavators included the adoption of unsafe work practices, unsuitable ground conditions and the operation of a mini-excavator on an incline (Edwards and Holt, 2010). Other reported types of plant-related safety incidents involve operators being struck by falling objects while operating their machines or falling from the plant while entering, operating or disembarking from it. Falls from plant accounted for $40 \%$ of all non-fatal incidents and eight per cent of fatal incidents involving workplace transport in the UK in 2007-08 (Holt and Edwards, 2011).

\section{Aims}

This research aimed to investigate the circumstances surrounding fatal incidents involving plant in the Australian construction industry. Drawing on coronial investigation findings the research utilised a systemic incident causation model to explore the causes of incidents identified as involving an item of plant (see the description of the 'theoretical framework' below). The analysis sought to provide greater insight into how and why fatal incidents involving plant occur in the construction industry. In undertaking this in-depth analysis, the objective was to inform recommendations for the prevention of fatal incidents involving plant.

\section{Theoretical framework}

This analysis of fatal incidents involving plant adopted an incident causation model developed by researchers at Loughborough University (hereafter referred to as the 'Loughborough model') as its theoretical framework. This model proposes three levels of incident causation (HSE 2003). First, the immediate circumstances of an incident are those easily identifiable circumstances surrounding the incident itself. These can include the suitability, usability and condition of tools, equipment and materials, the behaviour and capabilities of workers and features of the physical site environment, such as layout, lighting and weather conditions. Second, the Loughborough model posits that these immediate circumstances are preceded by shaping factors, such as the level of supervision, site constraints, worksite 
design, poor communication within work teams housekeeping and the state of workers' health and fatigue. Third, these shaping factors are believed to occur as a result of originating influences, such as client requirements, features of the economic climate, the prevailing level of construction education, design of the permanent building/structure, the quality of project management and the prevailing safety culture and risk management approach. Thus, the Loughborough model acknowledges that workplace safety incidents occur as a result of a complex interplay of causal factors, some of which originate "upstream" of the construction site.

\section{Research Methods}

\section{Case selection}

The National Coronial Information System (NCIS) is a national database that captures data relating to deaths investigated by an Australian coroner. The database is managed by the Victorian Institute of Forensic Medicine and was developed to assist coroners to better identify recurrent hazards within the community.

The cases were identified from among closed cases identified in the database determined by the coroner to be work-related. The following selection criteria were applied:

(i) the decedent was a construction worker. Incidents in which the decedent was a member of the public were excluded.

(ii) the incident resulting in death occurred on a construction worksite. Travel incidents occurring as the decedent travelled to and from work were excluded; and

(iii) the incident involved an item of plant. Incidents in which construction workers were struck by private vehicles that encroached into the worksite were excluded.

The NCIS database was used to examine the nature and circumstances of incidents that satisfied these criteria. Detailed information about the fatalities, such as the time of the incident, age and occupation of the decedent were identified. Further, the circumstances of each incident were described in coronial findings reports, allowing a more detailed analysis of incident causes than would otherwise be possible using national compensation-based data.

A total of 258 closed cases representing the work-related death of a construction worker occurring were identified in the database. Of these cases, 81 satisfied the eligibility criteria for inclusion in this analysis. Coroners' findings were analysed, using the Loughborough incident causation model to identify and code the causes of each fatal incident.

\section{Results}

\section{Demographic characteristics of decedents}

Most of the decedents $(n=79,97.5 \%)$ were male. Only two cases in which a female construction worker died as a result of a plant-related incident were found in the database, accounting for only $2.5 \%$ of the 81 cases. The age of the decedents ranged from 18 to 69 , with a mean of 43.01 years of age $(\mathrm{SD}=14.60)$. Figure 2 shows the number of cases identified for workers in different age ranges. Twenty four of the fatal incidents $(29.60 \%)$ occurred to persons aged between 46 and 55. 
Figure 2: Age of decedents

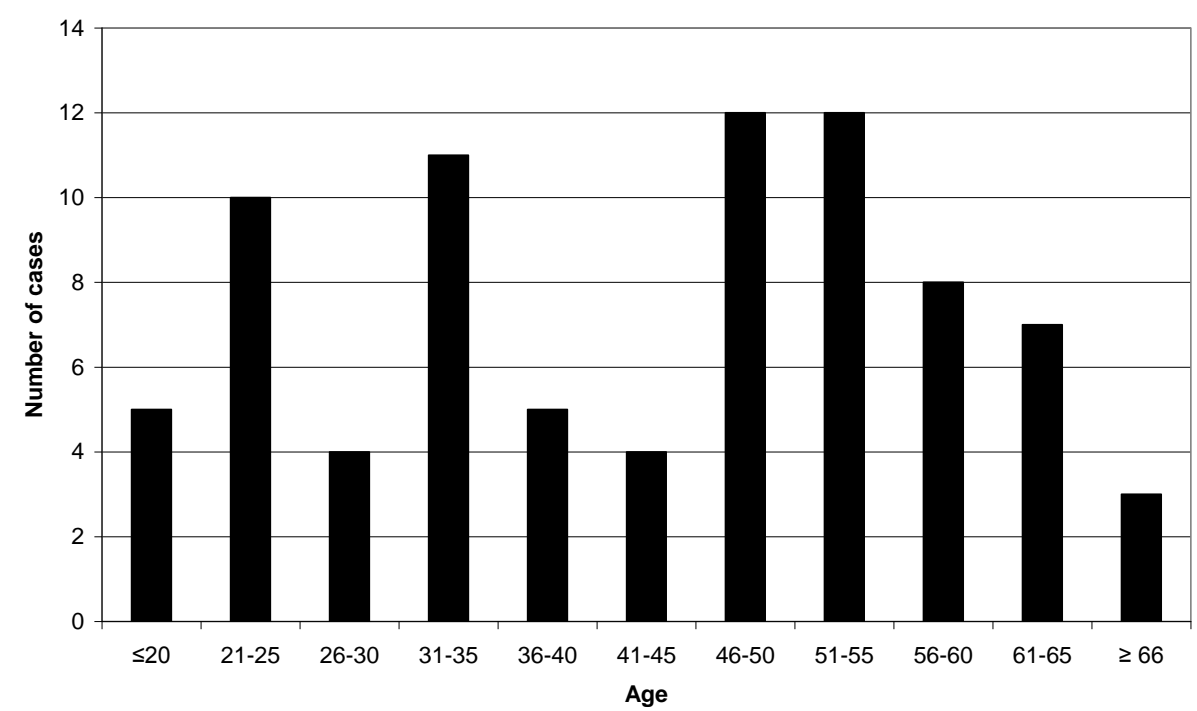

Roleloccupation of decedents

In 39 cases $(48.1 \%)$, the decedent was the driver/operator of the plant involved in the incident. In the remaining 42 cases $(51.9 \%)$, the decedent was another worker in the vicinity of the plant at the time of the incident. Figure 3 shows the decedents by occupational grouping. Plant operators were involved in more work-related deaths involving mobile plant than any other occupation $(n=17,21.0 \%)$. Another sixteen $(19.8 \%)$ of the incidents involved labourers. In thirteen $(16.0 \%)$ cases, the decedent was a truck driver. Nine supervisors/managers and eight traffic controllers were killed, accounting for $11.1 \%$ and $9.9 \%$ of the incidents respectively. Four unspecified tradesmen and four concretors were among the persons killed, each accounting for $4.9 \%$ of the total. Two electricians and two fencing contractors were among those killed, each accounting for $2.5 \%$ of the incidents. The remaining decedents included a plumber, a surveyor, a sand blaster and a rigger.

Figure 3: Occupation of decedents

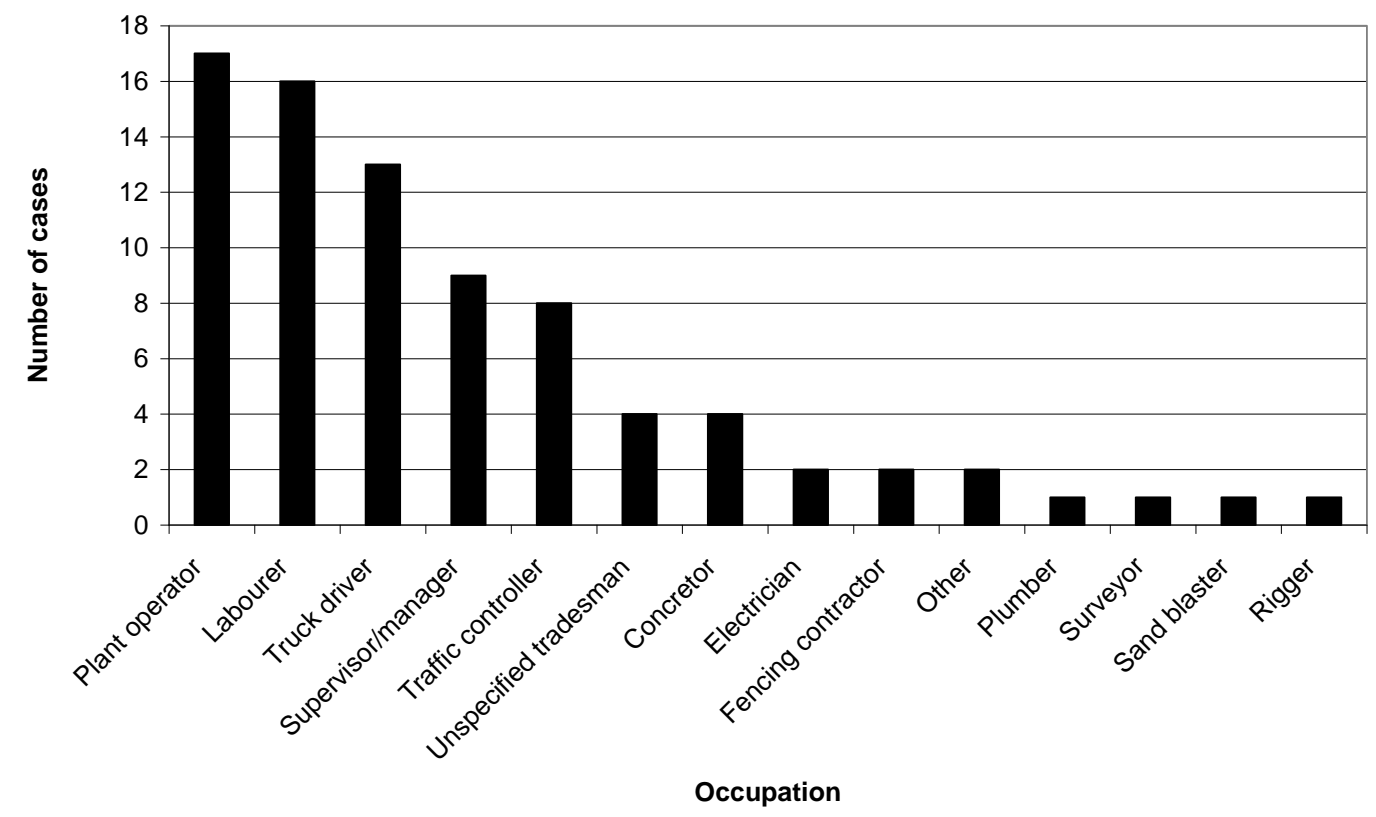

Time of the incident

The time of the incident could be identified in only 55 cases (67.9\%). Figure 4 shows the number of cases occurring at different times of the working day. The number of cases peaked between 10.00 and 10.59 am, with nine cases $(11.1 \%)$ occurring in this time frame. A further 13 cases $(16.1 \%)$ occurred between 
three and five o'clock in the afternoon. These peaks coincide with the period immediately prior to the mid-morning break and end of the work day, suggesting that fatigue may be a causal issue. The majority of cases occurred during daylight hours, with only five cases $(6.1 \%)$ recorded after six pm.

Figure 4: Number of cases by time of occurrence

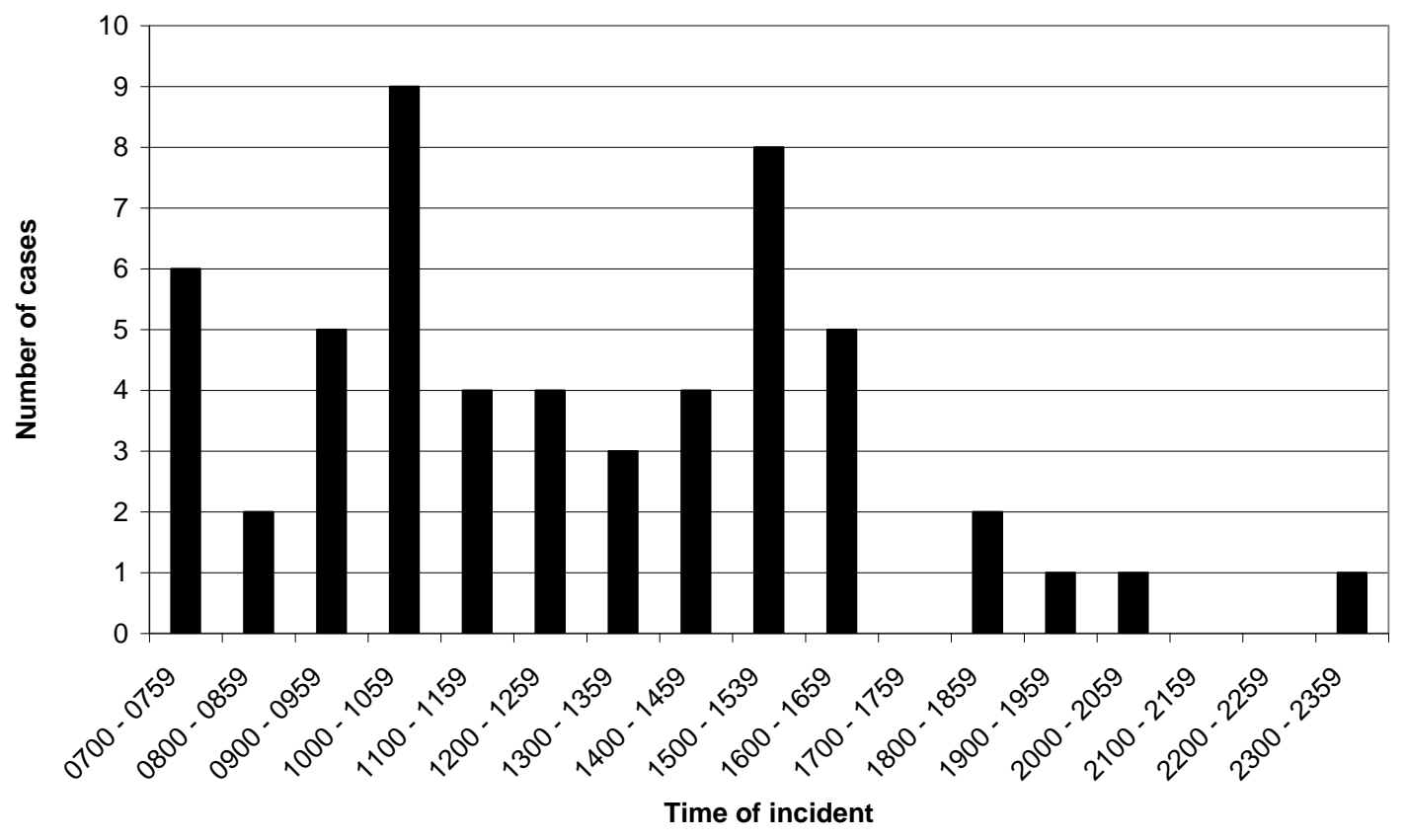

\section{Type of plant involved}

The type of plant involved in the incident was identified in 80 of the 81 incidents. Figure 5 shows the number of incidents by plant type. Trucks and excavators/backhoes were the most frequently identified item of plant involved in the fatal incidents, each accounting for 17 deaths (21.0\% of cases). Cranes were involved in 15 fatal incidents (18.5\% of the total). Compactors/rollers and forklifts were each involved in six fatal incidents (7.4\% of the total), while 'cherry pickers' and front end loaders were each involved in four fatal incidents ( $4.9 \%$ of the total). Concrete pumps and bulldozers/graders were each involved in three fatal incidents, each accounting for $3.7 \%$ of the total.

\section{Figure 5: Type of plant}

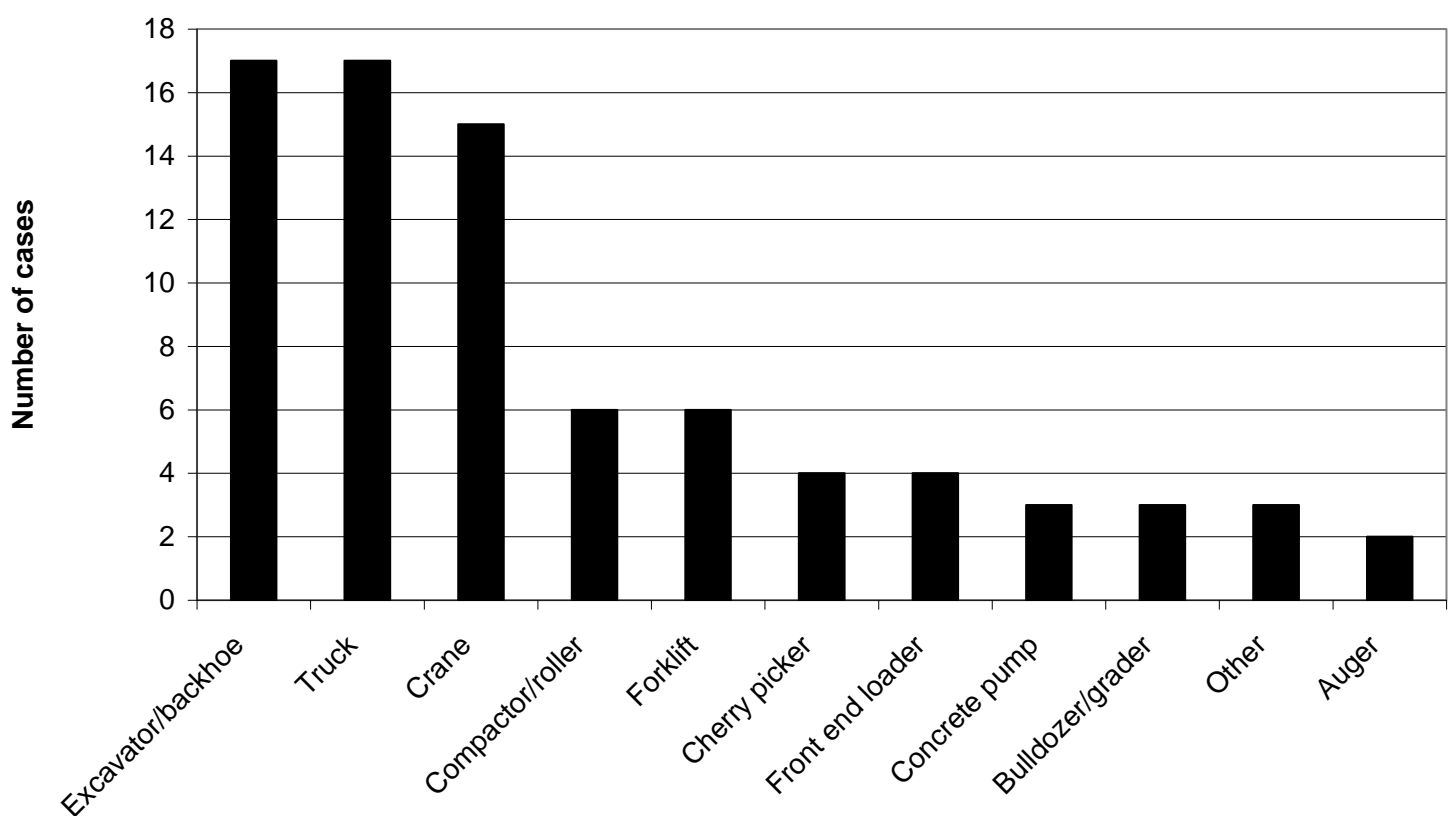

Type of plant 


\section{Incident classification}

The most frequently occurring types of incident involved people being run over by an item of plant $(n=27,33.3 \%)$ or people being struck by a moving object $(n=23,28.4 \%)$. In ten cases $(12.3 \%)$ the incident involved an item of mobile plant overturning. Other incidents included electrocutions $(\mathrm{n}=7$, 8.6\%), falls from plant $(\mathrm{n}=4,4.9 \%)$, instances of persons being crushed between mobile plant and another object $(n=5,6.2 \%)$, entanglements $(n=3,3.7 \%)$ and engulfments $(n=2,2.5 \%)$.

Table 1: Type of incident by type of plant

\begin{tabular}{|c|c|c|c|c|c|c|c|c|c|c|c|}
\hline \multicolumn{12}{|c|}{ Type of plant } \\
\hline 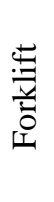 & 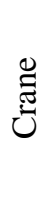 & 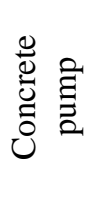 & 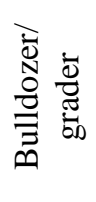 & 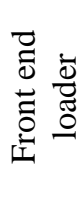 & 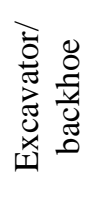 & 窇 & $\frac{\dot{\Phi}}{\stackrel{D}{0}}$ & 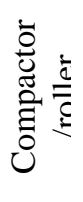 & 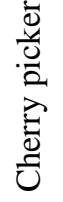 & 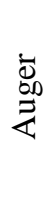 & 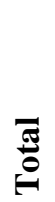 \\
\hline 1 & 1 & 0 & 1 & 1 & 3 & 0 & 0 & 3 & ( & 0 & 10 \\
\hline 4 & 11 & 2 & 1 & 0 & 5 & 0 & 0 & 0 & & 0 & 23 \\
\hline 0 & 3 & 1 & 0 & 0 & 1 & 1 & 0 & 0 & ( & 1 & 7 \\
\hline 0 & 0 & 0 & 0 & 0 & 0 & 1 & 1 & 0 & ( & 1 & 3 \\
\hline 0 & 0 & 0 & 0 & 0 & 0 & 3 & 1 & 0 & 1 & 0 & 5 \\
\hline 0 & 0 & 0 & 0 & 0 & 2 & 0 & 0 & 0 & ( & 0 & 2 \\
\hline 1 & 0 & 0 & 0 & 0 & 0 & 0 & 0 & 0 & 3 & 0 & 4 \\
\hline 0 & 0 & 0 & 1 & 3 & 6 & 12 & 1 & 3 & ( & 0 & 26 \\
\hline 6 & 15 & 3 & 3 & 4 & 17 & 17 & 3 & 6 & 4 & 2 & 80 \\
\hline
\end{tabular}

Table 1 shows the type of incident occurring for each type of plant. There are noticeable differences in the proportion of incident types occurring for each plant type. The most frequent type of incident involving cranes was 'struck by' moving object incidents, accounting for $73.3 \%$. The most common truck incident type, accounting for $70.6 \%$ of all truck incidents, involved the decedent being run over by the truck. Incidents involving excavators/backhoes were more varied, with $35.3 \%$ of cases being 'runovers,' $29.4 \%$ being 'struck by' moving objects and $17.6 \%$ being 'overturning' incidents. Seventy five per cent of fatal incidents involving cherry pickers were falls from the plant.

\section{Incident causation}

Narrative descriptions of the incidents provided in the coronial findings were analysed to, where possible, identify the immediate circumstances, shaping factors and originating influences that contributed to each incident. The Loughborough model of incident causation was used to inform this analysis (HSE, 2003). The results are presented in Table 2. 
Table 2: Incident causes

\begin{tabular}{|c|c|c|c|c|c|c|c|c|}
\hline \multicolumn{3}{|c|}{ Immediate circumstances } & \multicolumn{3}{|c|}{ Shaping factors } & \multicolumn{3}{|c|}{ Originating influences } \\
\hline Cause & $\mathbf{N}$ & $\%$ & Factor & $\mathbf{N}$ & $\%$ & Influence & $\mathbf{N}$ & $\%$ \\
\hline Site layout & 39 & 48.1 & Site constraints & 19 & 23.5 & Safety culture & 13 & 16.0 \\
\hline Unsafe actions & 36 & 45.0 & Inadequate supervision & 18 & 22.2 & $\begin{array}{l}\text { Construction process } \\
\text { design }\end{array}$ & 13 & 16.0 \\
\hline $\begin{array}{l}\text { Communication } \\
\text { failure }\end{array}$ & 14 & 17.3 & Plant design & 17 & 21.0 & Permanent works design & 7 & 8.6 \\
\hline Lighting & 5 & 6.2 & Knowledge/skill & 16 & 19.8 & Risk management & 7 & 8.6 \\
\hline $\begin{array}{l}\text { Equipment } \\
\text { condition }\end{array}$ & 4 & 4.9 & Attitudes/motivation & 8 & 9.9 & Project management & 4 & 4.9 \\
\hline $\begin{array}{l}\text { Local worksite } \\
\text { hazards }\end{array}$ & 3 & 3.7 & Experience & 2 & 2.5 & Construction education & 3 & 3.7 \\
\hline $\begin{array}{l}\text { Equipment } \\
\text { (un)suitability }\end{array}$ & 2 & 2.5 & Work scheduling & 2 & 2.5 & Economic climate & 1 & 1.2 \\
\hline $\begin{array}{l}\text { Workers' } \\
\text { capability }\end{array}$ & 1 & 1.2 & Housekeeping & 1 & 1.2 & & & \\
\hline Weather & 1 & 1.2 & & & & & & \\
\hline
\end{tabular}

\section{Immediate circumstances}

Site layout was a relevant factor in $48 \%$ of the incidents included in the analysis. In many of these cases the coroner identified a failure to adequately segregate plant and people at the worksite as the cause of the incident. For example, in one case a plumber was killed when a mini-excavator fell into the trench in which he was working. The mini-excavator was being used to backfill the trench when it reportedly travelled too close to the edge of the trench, causing the trench walls to collapse. The mini-excavator then slid in to the collapsed trench, fatally injuring the decedent. Unsafe actions were also identified as a relevant factor in $45 \%$ of the incidents. In many cases, the decedent was a plant operator who had disembarked from the plant or was undertaking maintenance without switching off the engine or otherwise ensuring that plant could not be inadvertently started or moved. For example, in one case a concrete truck driver was fatally injured when he partially entered his truck's 'agitator bowl' while the engine was still running and the bowl started to rotate. Another case involved a truck driver who was run over by his prime mover when he disembarked without engaging the parking brake.

Communication failures were identified as a relevant factor in $17 \%$ of the incidents. For example, in one case a worker was struck by an excavator being used to remove trees from a worksite. Immediately prior to the incident the decedent had been attaching slings to the trees. The excavator operator was incorrectly advised by another worker that the decedent had left the area of the tree removal operation. The excavator operator continued to remove trees and during this operation the decedent was run over when working in one of the excavator's 'blind spots.' Lighting conditions were identified as relevant immediate circumstances in six per cent of cases. For example, in one case the decedent was directing a hydraulic tip truck when the truck struck powerlines. The decedent was leaning against the side of the truck and was electrocuted. At the time of the incident it was dark and foggy and the decedent, who was not familiar with the area, could not see the powerlines clearly.

\section{Shaping factors}

Site constraints and supervision were identified as shaping factors in $24 \%$ and $22 \%$ of the cases respectively. For example, in one case a backhoe driver was run over by a reversing tip truck when he was asked to stop his machine to allow the truck to remove dirt from the vicinity of a trenching operation. The coroner found that the contractor had not provided an effective system of supervision at the worksite and failed to ensure that pedestrians were adequately segregated from moving equipment.

Design of the plant itself was identified as a possible shaping factor in $21 \%$ of the cases. For example, a bulldozer operator was run over by his machine when he fell from its tracks while undertaking engine repair work. The need to stand on the tracks to open the engine cover contributed to this incident. Plant design was also a possible factor in a number of incidents in which plant operators' ability to see other workers was restricted due to 'blind spots.' For example, in one case the decedent, who was working at a 
road construction site, was on foot behind a large reversing water truck which was being used to dampen down the earthworks. The driver of the water truck was reversing the truck, checking his mirrors as he was doing so. However, he could not see the decedent, who was run over by the reversing truck. As a result of this incident the company fitted a rear-facing closed circuit television (CCTV) camera into the cab of all water tankers and graders and changed the reverse warning alarm sound. The company also implemented emergency procedures using air horns as a warning sound and implemented coordinated use of an ultra high frequency (UHF) radio system as a communication method for plant operators. Workers' knowledge was identified as a relevant shaping factor in $20 \%$ of the cases. For example, a worker who was crushed between the outside rail of a scissor lift he was operating and a false ceiling was not familiar with the operation of the scissor lift and had received no training in its use.

\section{Originating influences}

Fewer originating influences could be identified in the coronial findings. However, in $16 \%$ of cases, the prevailing workplace safety culture could be identified as a factor contributing to the occurrence of the incident. For example, in one case a concrete pump broke while being operated with the boom fully extended. The falling boom fatally injured a concretor. In this instance the coroner observed that safety concerns relating to plant maintenance had been raised on several occasions prior to the incident but no action had been taken. In another $16 \%$ of cases, the design of the construction process was identified as an originating influence and, in nine per cent of cases the design of the permanent works was identified as a relevant contributing factor. For example, in one case extra large pre-fabricated insulation panels were being installed at a cold storage facility. As these panels were larger than usual, an additional scissor lift was being used in the erection process. The process of erection involved tying the panels to the scissor lift using a rope, which the coroner noted was not a safe work process. During the operation, the decedent fell from the scissor lift. In this case, the extra large size of the panels (a permanent design issue) and the unsafe installation (a process design issue) were significant originating influences. Failures in risk assessment processes and project management issues were identified as relevant factors in approximately nine and five per cent of the incidents respectively. Project management issues typically involved a lack of coordination between trades and/or pressures associated with the work schedule.

\section{Discussion}

\section{The imperative to reduce the risk of plant incidents}

Incidents involving plant remain a persistent problem for the Australian construction industry. The imperative to manage risks associated with the use of plant is a key element of the proposals for national harmonisation of workplace safety legislation. For example, Section 5.1.34 of the Model Work Health and Safety Regulations requires anyone with management control of powered mobile plant at a workplace to eliminate the risk of: (a) the plant overturning, (b) things falling on the operator of the plant; (c) the operator being ejected from the plant; or (d) the plant colliding with any person or thing. Further, the Regulations state that, where it is not reasonably practicable to eliminate the risk of these occurrences, the risk must be reduced so far as is reasonably practicable.

It is important that strategies to prevent incidents involving plant are informed by an understanding of how and why these incidents occur. This analysis reveals that different plant items are associated with different types of incident. However, the most frequently occurring incident type involved persons being run over by moving plant. 'Runover' incidents were particularly common in the case of trucks and excavators. The analysis of incident causes revealed that 'runover' incidents occurred for a number of reasons. Prominent among these reasons were issues with site layout, operators' inability to adequately see workers on foot and failures in communication and warning systems.

\section{The potential to reduce risk through improvements to site layout and resource planning}

The management of site movements (of materials, plant and people) is important in terms of reducing travel distances and costs and increasing productivity. However, it is also possible to ensure that plant moves around a site in such a way as to avoid high risk areas. The design of site layouts which segregate pedestrian routes from vehicles routes, minimise travel distances and enable objects in front of plant to be seen can help prevent incidents. Several innovative approaches offer the potential to reduce the risk of 
collisions between plant and people, through enabling better design of the site layout and work sequencing. These are described below.

Lam et al. (2007) explored the use of an 'ant colony optimisation' (ACO) algorithm to optimise routing, assignment and scheduling. In the ACO model, Lam et al. (2007) considered the facilities required by a project, the degree of closeness and interaction between resources, materials, equipment and facilities and the importance placed upon the different factors associated with the site layout (one of which was the safety risk associated with clashes between people and plant). The ACO algorithm was used manage site layout and planning in a hypothetical medium-sized construction project.

A Virtual Design and Construction (VDC) approach has also been recommended for use in construction planning (Li et al., 2009). By virtually 'walking through' the construction process, unsafe areas in construction site operations (including clashes between people and plant) can be detected and proper solutions made possible. VDC is also able to facilitate improved communication between project stakeholders, including clients, design consultants and constructors, which is an important aspect of improving OHS performance in construction projects.

Path planning analysis has been developed as a means of managing multi-objective coordination problems for site transport cost, safety and visibility (Soltani and Fernando, 2004). A fuzzy-based multiobjective optimisation approach has been used to support the design of work processes and the movement of people and vehicles on construction sites. Soltani and Ferando (2004) developed computer-based application that analyses pedestrian and plant movements to identify the best available routes based upon the distance of travel, cost, visibility and safety performance of these routes. Tam et al. (2007) developed a similar system specifically for earthmoving operations. However, they developed a system that also considered the type of plant used in the project as a factor that needed to be modelled and optimised. Thus, the resulting system supports both plant selection and path analysis to optimise the selection of the type of earthmoving plant in relation to the routes of travel. The incorporation of information such as gradient, width and other local conditions into the model enables the compatibility of a particular route with a specific item of plant to be optimised. This is important because site constraints, such as spatial characteristics, gradients etc. were the most common shaping factor associated with fatal incidents in our analysis. Also, Edwards and Holt (in press) emphasise the importance of selecting plant that will perform safely in the context in which it is to be used.

The potential to reduce risk using innovative proximity detection and warning systems Blind spots, i.e., areas around items of plant that cannot be seen by the operator are particularly common at the rear and sides of a machine (Teizer et al. 2010). Back-up alarms and high visibility clothing are two forms of risk mitigation to help overcome blind spot and visibility hazards. However, these are both examples of 'passive' safety technologies (Fullerton et al. 2009). Alternative technologies are described as 'active' because they possess sensory devices and real-time monitoring/warning capability. Several innovative approaches offer the potential to actively monitor the risk of collisions between plant and people. These are described below.

Ruff (2002) describes the use of radar technology to monitor activity in blind spots around plant. However, the detection zone of a radar system depends on the size, shape, and composition of the object being detected and the mounting height and tilt angle of the radar antenna. Coverage of all blind spots around the plant therefore requires a number of radar units (Health and Safety Executive, 2001). Also, when testing a radar-based monitoring system fitted to a reversing dump truck, Ruff (2006) reported that immediate action was required in only $41 \%$ of cases in which an alarm was sounded, concluding that this system is best used in conjunction with a visual method of monitoring, such as video cameras.

Radio-frequency identification devices (RFIDs) have also been suggested as a way to monitor hazardous situations involving plant (Fullerton et al. 2009; Teizer et al. 2010). An antenna is mounted on plant and workers in work zone wear tags which can be read by the RFID antenna. When the antenna detects the tag, an alarm sounds providing the plant operator and workers with a warning of the potential conflict. Other active warning systems utilise Global Positioning System (GPS) technology (see, for example, 
Oloufa et al. 2003). Ruff and Holden (2003) developed a GPS-based proximity warning system which provides an operator with the location of objects, people and vehicles in the 'blind spot' areas of their plant.

Other proposed 'hybrid' systems combine different technologies. For example Riaz et al. (2006) describe a conceptual system called 'SightSafety' which combines GPS technology, smart sensors and wireless networks. This system could be pre-set to activate a response appropriate to the proximity between workers and plant. For example, in a high risk situation, plant could be immediately immobilised whereas, in a moderate risk situation audio and/or visual alarms would be activated.

Active monitoring systems also have the potential to record data relating to 'close calls' which can be used to inform future improvements in worksite design and systems of work in relation to the positioning of workers and plant.

\section{The usefulness of the 'Loughborough model'}

The Loughborough model of incident causation was useful in the analysis of causes of plant-related fatal incidents, providing insight into the immediate circumstances, shaping factors and originating influences. The findings are consistent with previous research linking 'upstream' originating influences, such as permanent works design and design of the construction process in causal pathways via intermediate shaping factors to the immediate circumstances surrounding incidents.

Many reports in the NCIS identified workers' own actions as the immediate cause of the incident. While unsafe actions on the part of decedents and others are undoubtedly an important causal factor in incident occurrence, systemic models of incident causation seek to 'explain' workers' behaviour in relation to features of the entire system of work, including organizational and management factors. There is arguably a need to understand workers' unsafe behaviour in context in order to properly address the 'root' causes of behavioural safety issues.

It is noteworthy that in the coronial findings, shaping factors and originating influences were identified in fewer cases than immediate circumstances. It is possible that, in the case of some incidents, immediate circumstances are not traced back to their 'root' causes. The use of a systemic causation model, such as the Loughborough model, may yield more comprehensive data relating to incident causation if used to inform investigations. Notwithstanding this, the analysis of plant-related fatalities does suggest that narratives contained in the NCIS database can assist in the identification and management of systemic safety risks related to plant use in construction.

\section{Conclusions}

This analysis provides preliminary information about how and why fatal incidents involving plant occur in the Australian construction industry. This analysis provides more in-depth information than that provided by workers' compensation statistics, which typically only identify the agency and mechanism of injuries. The analysis reveals that most plant-related fatal incidents involve excavators, trucks and cranes and that different classifications of plant are associated with different types of incident. The most common incident types involved people being run over by moving plant or struck by a moving object, often a component part of plant. More research is recommended to assess the potential for innovative site planning and optimisation approaches and/or new technologies for active monitoring and warning systems to help in the prevention of 'runover' and 'struck by' incidents involving plant. The research also provides some evidence that 'upstream' originating influences are a relevant factor in fatal incidents involving plant in the construction industry. The Loughborough model of incident causation was a useful framework for informing the analysis and the use of robust systemic incident causation model can contribute to the identification of causes beyond the immediate circumstances of an incident.

\section{References}

Burgess, M. \& McCarty, M. (2009) Effectiveness of non-tonal audible movement warning alarms for construction sites Proceedings of ACOUSTICS. Adelaide, Australia

Edwards, D. J. \& Nicholas, J., (2002), The state of health and safety in the UK construction industry with a focus on plant operators, Structural Survey, 20, $78-87$. 
Edwards, D. J. \& Holt, G. D., (2009b), New stability field tests for construction excavators, Engineering, Construction and Architectural Management, 16, 337-352.

Edwards, D. J. \& Holt, G. D., (2009a), Construction plant and equipment management research: thematic review, Journal of Engineering, Design and Technology, 7, 186-206.

Edwards, D. J. \& Holt, G. D., (2010), Case study analysis of construction excavator H\&S overturn incidents, Engineering, Construction and Architectural Management, 17, 493-511

Edwards, D. J. \& Holt, G. D., (2008), Health and safety issues relating to construction excavators and their attachments, Engineering, Construction and Architectural Management, 15, 321-335.

Edwards, D. J. \& Holt, G. D. (in press), Mini-Excavator Safety: Towards Innovative Stability Testing, Procurement and Manufacture. Journal of Construction Engineering and Management, doi:10.1061/(ASCE)CO.1943-7862.0000383

Health and Safety Executive (2001), Improving the safety of workers in the vicinity of mobile plant. Contract Research Report 358/2001. Norwich, UK.

Health and Safety Executive, (2009) The safe use of vehicles on construction sites. Downloaded from http://books.hse.gov.uk/hse/public/saleproduct.jsf?catalogueCode=9780717662913, $15^{\text {th }}$ July 2011.

Hinze, J., Huang, X. \& Terry, L. (2005) The Nature of Struck-by Accidents. Journal of Construction Engineering and Management, 131, 262-268.

Hinze, J. W. \& Teizer, J. (2011) Visibility-related fatalities related to construction equipment. Safety Science, 49, 709-718.

Holt, G. D., \& Edwards, D. J., (2011), Slips, trips, falls and other risks when accessing, egressing or working upon workplace transport, The Off-Highway Plant and Equipment Research Centre, Dudley, UK.

Lam, K.-C., Ning, X. \& Thomas, N. (2007) The application of the ant colony optimization algorithm to the construction site layout planning problem. Construction Management and Economics, 25, 359-374.

Li, H., Lu, W. \& Huang, T. (2009) Rethinking project management and exploring virtual design and construction as a potential solution. Construction Management and Economics, 27, 363-371.

McCann, M,. (2006), Heavy equipment and truck-related deaths on excavation work sites. Journal of Safety Research, 37, 511517.

Myers, M. L., (2004), Compactor overturns and rollover protective structures. The Center to Protect Workers' Rights, Silver Spring MD.

Pratt, S. G., Fosbroke, D. E. \& Marsh, S. M. (2001) Building safer highway work zone. Department of Health and Human Services.

Riaz, Z., Edwards, D. J. \& Thorpe, A., (2006) SightSafety: A hybrid information and communication technology system for reducing vehicle/pedestrian collisions. Automation in Construction, 15, 719-728.

Ruff, T. (2006) Evaluation of a radar-based proximity warning system for off-highway dump trucks. Accident Analysis \& Prevention, 38, 92-98.

Ruff, T. M. \& Holden, T. P. (2003), Preventing collisions involving surface mining equipment: a GPS-based approach. Journal of Safety Research, 34, 175-181.

Soltani, A. R. \& Fernando, T. (2004) A fuzzy based multi-objective path planning of construction sites. Automation in Construction, 13, 717-734.

Tam, C. M., Tong, T. K. L. \& Wong, B. W. L. (2007) An integrated system for earthmoving planning. Construction Management and Economics, 25, 1125-1135.

Teizer, J., Allread, B. S., Fullerton, C. E. \& Hinze, J. (2010), Autonomous pro-active real-time construction worker and equipment operator proximity safety alert system. Automation in Construction, 19, 630-640.

Teizer, J., Allread, B. S. \& Mantripragada, U. (2010) Automating the blind spot measurement of construction equipment. Automation in Construction, 19, 491-501.

Teizer, J., Caldas, C. H. \& Haas, C. T., (2007), Real-Time Three-Dimensional Occupancy Grid Modeling for the Detection and Tracking of Construction Resources. Journal of Construction Engineering and Management, 133, 880-888. 